$\mathrm{TM}-1213$

0102.000

Sept. 15,1983

\title{
$20 \mathrm{TeV}$ COLLIDING BEAM FACILITIES
}

F. R. Huson

\section{Introduction}

Consideration of multi-TeV facilities occurred at many ICFA meetings, however enthusiasm in the U.S. began at the DPF 1982 summer workshop ${ }^{2}$ held at Snowmass, Colorado. The physics that might be performed at such a facility was studied as well as possible designs for the accelerator. Many ideas were put forward that might reduce the cost of a collider. During the past year work on possible superconducting magnets for the accelerator has been done at various labs. In March, a workshop was held at Cornell University ${ }^{3}$ on the accelerator. The conclusion of this workshop was that a $20 \mathrm{TeV}$ on $20 \mathrm{TeV}$ proton-proton collider is technically feasable, that construction could begin after 2.5 to 4 years of research and development, and the cost would be 1.3 to 2 billion dollars.

To put this machine into perspective one must consider the existing facilities listed in table I. There are about 23 high energy physics laboratories in the world that are being operated or constructed. Most of these labs have an effective energy of less than $100 \mathrm{GeV}$ and study principally the known quarks and leptons. The only accelerator operating at an effective energy greater than $100 \mathrm{GeV}$ is the CERN proton-antiproton system.. As has been presented at this conference in other papers their success has been great in a very short time, the discovery of the vector bosons $W$ and $Z$. The only machine approved that will have an effective energy greater than $1000 \mathrm{GeV}$ is the Russian accelerator UNK. The effective energy of a $20 \mathrm{TeV}$ on $20 \mathrm{TeV}$ proton-proton collider would be about $15 \mathrm{TeV}$ !

\section{Conceptual Design}

The overall layout of the facility is an oval of circumference 60 to 150 kilometers with the 2 straight sections each about 5 kilometers long. Each of these straight sections could have 6 interaction regions. This would be done by splitting the beam by about 50 meters and having 3 interaction regions on each branch. The longitudinal distance between interaction regions would be about 1 kilometer. With bending magnets in a small tunnel in this 1 kilometer, the interaction regions should be sufficiently isolated from each other. The straight sections would also have regions at each end for machine devices. At one of the straight sections the injector would be located and perhaps a $30 \mathrm{GeV}$ electron accelerator for electron-proton collisions. Fig. 1 illustrates a possible layout of a straight section. 
Table I. High Energy Accelerator Facilities.

The active high-energy accelerator facilities of the world are 1isted below. The accelerators are divided into effective energy categories to emphasize the major experiments performed on them.

A. ACCELERATORS TO STUDY THE ENERGY REGION BELOW VECTOR BOSONS

\begin{tabular}{|c|c|c|c|c|}
\hline $\begin{array}{l}\text { Accelerator } \\
\text { (first beam) }\end{array}$ & Location & Particles & Energy & $\begin{array}{l}\text { Eff. } \\
\text { Energy }\end{array}$ \\
\hline $\begin{array}{l}\text { 1. PS }(1959) \\
\text { 2. AGS }(1960) \\
\text { 3. SERP }(1967)\end{array}$ & $\begin{array}{l}\text { Geneva } \\
\text { Long Island } \\
\text { Serpukhov }\end{array}$ & $\begin{array}{l}p(p) \\
p(p) \\
p(p)\end{array}$ & $\begin{array}{l}28 \mathrm{GeV} \\
33 \\
76\end{array}$ & $\begin{array}{l}2.4 \mathrm{GeV} \\
2.6 \\
4.0\end{array}$ \\
\hline $\begin{array}{l}\text { 4. ISR }(1971) \\
\text { 5. SPS }(1976) \\
\text { 6. ED }(1983)\end{array}$ & $\begin{array}{l}\text { Geneva } \\
\text { Geneva } \\
\text { Batavia }\end{array}$ & $\begin{array}{l}p p \\
p(p) \\
p(p)\end{array}$ & $\begin{array}{l}2 \times 31 \\
400 \\
1000\end{array}$ & $\begin{array}{l}20 \\
9.1 \\
15\end{array}$ \\
\hline 7. Linac (1966) & Palo Alto & $e(p)$ & 24 & 3.0 \\
\hline 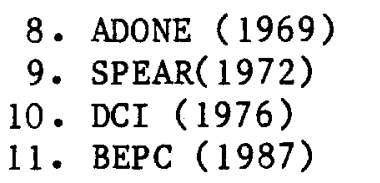 & $\begin{array}{l}\text { Frascati } \\
\text { Palo Alto } \\
\text { Orsay } \\
\text { Beijing }\end{array}$ & $\begin{array}{l}e^{+} e^{-} \\
e^{+} e^{-} \\
e^{+} e^{-} \\
e^{+} e^{-}\end{array}$ & $\begin{array}{l}2 \times 1.5 \\
2 \times 4.2 \\
2 \times 1.8 \\
2 \times 2.8\end{array}$ & $\begin{array}{l}3.0 \\
8.4 \\
3.6 \\
5.6\end{array}$ \\
\hline $\begin{array}{l}\text { 12. PETRA (1978) } \\
\text { 13. CESR (1979) } \\
\text { 14. PEP }(1980) \\
\text { 15. VEPPIV }(1982) \\
\text { 16. DORIS }(1983) \\
\text { 17. TRISTAN }(1986)\end{array}$ & $\begin{array}{l}\text { Hamburg } \\
\text { Cornell } \\
\text { Palo Alto } \\
\text { Novosibirsk } \\
\text { Hamburg } \\
\text { Ibaraki }\end{array}$ & $\begin{array}{l}e^{+} e^{-} \\
e^{+} e^{-} \\
e^{+} e^{-} \\
e^{+} e^{-} \\
e^{+} e^{-} \\
e^{+} e^{-}\end{array}$ & $\begin{array}{l}2 \times 19 \\
2 \times 8 \\
2 \times 18 \\
2 \times 7.5 \\
2 \times 6 \\
2 \times 30\end{array}$ & $\begin{array}{l}38 \\
16 \\
36 \\
15 \\
12 \\
60\end{array}$ \\
\hline
\end{tabular}

B. ACCELERATORS TO STUDY THE HUNDRED GeV REGION

\begin{tabular}{|c|c|c|c|}
\hline $\begin{array}{l}\text { 1. C̄p }(1981) \\
\text { 2. } F \bar{p} p(1986)\end{array}$ & $\begin{array}{l}\text { Geneva } \\
\text { Batavia }\end{array}$ & $\frac{\bar{p} p}{\bar{p} p}$ & $\begin{array}{l}540 \\
1800\end{array}$ \\
\hline $\begin{array}{l}\text { 3. SLC }(1987) \\
\text { 4. } \operatorname{LEP}(1988)\end{array}$ & $\begin{array}{l}\text { Palo Alto } \\
\text { Geneva }\end{array}$ & $\begin{array}{l}e^{+} e^{-} \\
e^{+} e^{-}\end{array}$ & $\begin{array}{l}100 \\
150+\end{array}$ \\
\hline 5. HERA (1990) & Hamburg & ep & $30 \times 800$ \\
\hline
\end{tabular}

C. ACCELERATORS TO STUDY ENERGY RANGE IN THE $1000 \mathrm{GeV}$ REGION

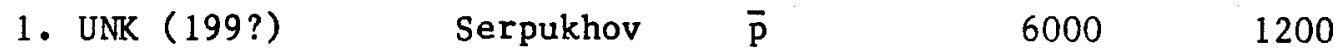




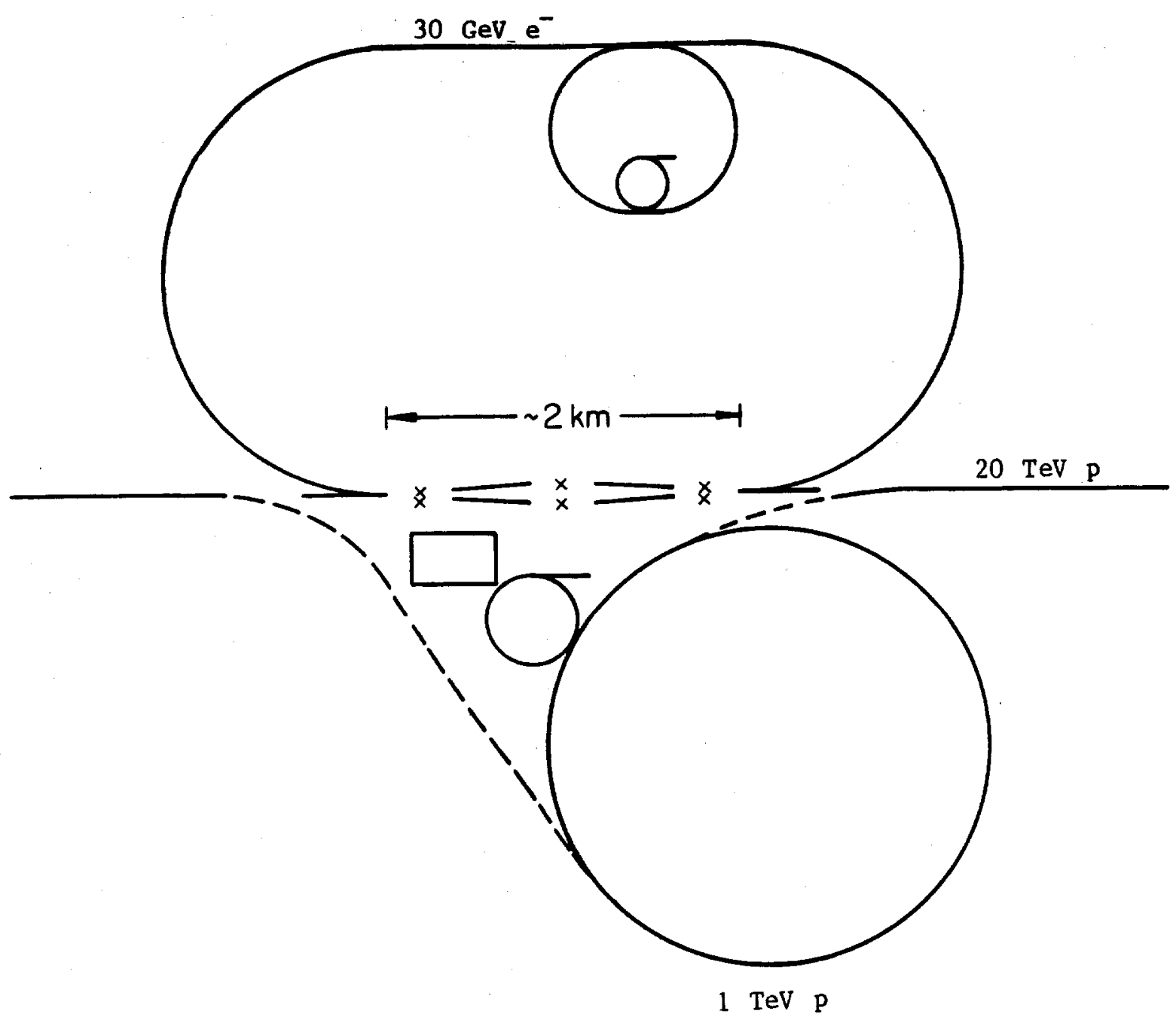

Fig. 1. A possible layout of one of the long straight sections of a $20-\mathrm{TeV}$ ring. The upper ring could be a $30-\mathrm{GeV}$ electron ring to provide ep collisions. The lower ring would be the injector. The $6 \mathrm{x}^{\prime} \mathrm{s}$ in the center mark interaction points. 
The injector for the storage ring would probably be a linac and two boosters. The linac would have an energy of about $2.5 \mathrm{GeV}$ so that at injection into the first booster a beam emittance of $\pi \mathrm{mm}$.mrad would not be blown-up by space charge forces. The first booster could be a rapid cycling $(15 \mathrm{~Hz}$ ) machine of 2.5 to $50 \mathrm{GeV}$ and the second booster could be similar to the energy doubler i.e. 50 to $1000 \mathrm{GeV}$. This injector could load the two rings of a proton-proton machine in less than an hour.

The choice of proton-proton versus proton-antiproton collider will probably be proton-proton because, for about the same cost, ten times the luminosity can be obtained. For antiprotons the cost of the source, larger magnet aperture required to separate the two beams, additional requirements on the injector and special devices for separating the beams is about equal to the cost of the second ring for protons. On the other hand, the proton and antiproton beams must only cross at the interaction point to minimize the beam-beam tune shift, this restricts the location of the bunches of beam such that they can only be at maximum betatron motion when passing on their separate closed orbits, thus the number of bunches of beam is less by a factor of ten.

If the average number of interactions per crossing is one and the crossings are 100 nanoseconds apart the luminosity will be about $10^{32}$ $\mathrm{cm}^{-2} \mathrm{~s}^{-1}$.

$$
\begin{aligned}
& \overline{\mathrm{n}}=1 \\
& \mathrm{r}=10 \text { megaHertz } \\
& \sigma=.5 \mathrm{mb} \text { inelastic cross section } \\
& \mathrm{L}=\dot{\mathrm{n}} \mathrm{r} / \sigma=2 \times 10^{32} \mathrm{~cm}^{-2} \mathrm{~s}^{-1}
\end{aligned}
$$

From the point view of the accelerator operation and the background in an experiment the beam intensity should be minimized. There are 4 variables in the luminoisty.

$$
\begin{aligned}
& \Delta \nu=\text { beam-beam tune shift } \\
& \varepsilon_{0}=\text { normalized emittance } \\
& \mathrm{n}_{\mathrm{b}}=\text { number of particles per bunch } \\
& \beta^{*}=\text { beta function at interaction point }
\end{aligned}
$$

only two of these are independent, thus $\Delta \nu$ is chosen to be maximum $(.003)$ and $\beta^{*}$ is chosen minimum (2 meters). From the two relations

$$
\begin{aligned}
& \mathrm{L} / \mathrm{r}=\left(2 \mathrm{n}_{\mathrm{b}} \Delta \nu \gamma\right) /\left(3 \mathrm{r}_{\mathrm{p}} \beta^{*}\right) \\
& \Delta \nu=3 \mathrm{n}_{\mathrm{b}}{ }_{\mathrm{r}} / \varepsilon_{0}
\end{aligned}
$$

one obtains

$$
\begin{aligned}
& \mathrm{n}_{\mathrm{b}}=7 \times 10^{9} \text { particles } \\
& \varepsilon_{0}=3 \pi \mathrm{mm} \cdot \mathrm{mrad}
\end{aligned}
$$


If more luminosity is required both the number of prticles per bunch and the emittance must increase and consequently the average number of interactions per crossing will increase, or the time between bunches must decrease.

Consideration of the interaction regions indicates that for headon collisions about 25 meters of free space can be obtained. Outside of this space magnets can be placed to separate the two beams at the next crossing away from the interaction point if the bunches are 100 ns apart. The beam size at the interaction point is about 4 microns.

\section{Magnets}

The most important piece of equipment in the accelerator is the magnet system. This is true from the stand point of overall cost of the facility and from operational efficiency and quality. Because of electrical power considerations the magnets must be superconducting. Table II lists the parameters for three different field values 3 , 5, and 8 Tesla. The low field case would be a superferric magnet, that is, superconducting coils to drive the field in iron. The medium field magnet would be of conventional design such as the Energy Doubler magnet. The high field magnet would require new technology such as $1.8^{\circ} \mathrm{K}$ helium operation or use of $\mathrm{Nb}_{3} \mathrm{Sn}$ for the superconductor. At the Cornell Workshop it was estimated that the superferric magnet developemt would require about 2.5 years whereas the high field research and development may take 4 years.

Table II. Various Parameters are Listed for Three Different Magnetic Fields.

\begin{tabular}{|c|c|c|c|}
\hline $\begin{array}{l}\text { Field } \\
\text { Bend radius } \\
\text { Average radius } \\
\text { Circumference }\end{array}$ & $\begin{array}{l}3 \\
22.2 \\
25 \\
100\end{array}$ & $\begin{array}{l}5 \\
13.3 \\
15 \\
60\end{array}$ & $\begin{array}{l}8 \text { Tesla } \\
8.3 \mathrm{~km} \\
10 \mathrm{~km} \\
40 \mathrm{miles}\end{array}$ \\
\hline $\begin{array}{l}\text { Tune } \\
\text { Number of quad } \sim 10 \mathrm{v} \\
\text { Number of arc dipoles }\end{array}$ & $\begin{array}{l}100 \\
1000 \\
2 \times 940\end{array}$ & $\begin{array}{l}60 \\
620 \\
12 \times 570\end{array}$ & $\begin{array}{l}40 \\
400 \\
24 \times 355\end{array}$ \\
\hline Stored energy per dipole & 330 & 400 & $450 \mathrm{~kJ}$ \\
\hline $\begin{array}{l}\text { Length of half cell } \\
\text { Length of dipole } \\
\text { Length of quad } \\
\text { Length of corr. } \\
\text { Space }\end{array}$ & $\begin{array}{l}157 \\
147 / 2 \\
5 \\
3 \\
2\end{array}$ & $\begin{array}{l}157 \\
147 / 12 \\
5 \\
3 \\
2\end{array}$ & $\begin{array}{l}157 \mathrm{~m} \\
147 / 24 \mathrm{~m} \\
5 \mathrm{~m} \\
3 \mathrm{~m} \\
2 \mathrm{~m}\end{array}$ \\
\hline
\end{tabular}

* Tune is chosen such that the beam size is always less than $1 \mathrm{~mm}$ $(\sigma=0.2 \mathrm{~mm})$

$$
\nu=\frac{R}{\beta}=\frac{R \varepsilon_{0}}{6 \pi \sigma^{2} \gamma}
$$


The arguments for the superferric magnet are simplicity, rel1ablity, small cross section and cost. The cost of a magnet system is dominated by the cost of the superconductor. The total weight of superconductor required for a machine is proportional to the number of ampere-turns.

$$
\text { Pounds of } s c=2 \pi R \rho N I / J
$$

where

$$
\begin{aligned}
\mathrm{R} & =\text { radius of accelerator } \\
\rho & =\text { density of } \mathrm{sc} \\
\mathrm{NI} & =\text { ampere-turns in magnet } \\
\mathrm{J} & =\text { current density in } \mathrm{sc} \sim 1 / \mathrm{B} \\
\mathrm{B} & =\text { Magnetic field }
\end{aligned}
$$

and since

$$
p=.3 B R
$$

then

$$
\text { pounds } f s c \sim N I \times p
$$

For fixed momentum the pounds of superconductor is proportional to the total ampere-turns and independent of the field. The total ampere-turns for different magnetic fields is given in figure 2 . Figure 3 is an example of a 3 Tesla magnet design.

The advantages of the medium field magnet are the technology exists and experience is being obtained with the Energy Doubler. The additional cost for the magnet system is compensated by the smaller cost for the tunnel and other linear costs.

The argument for the high field case is that technology should be pushed so that the most modern accelerator is constructed. This should result in the most versatile machine and not be much more in total cost.

The associated electronics and cryogenics of the magnet system can be serviced from about 20 entry points around the tunnel. A careful study needs to be done to assess the usefullness of robots in the tunnel. One can imagine a robot for alignment of the magnets, another for the transport of long magnets, others for transport of personnel and perhaps many for assembly of the magnets.

\section{Costs}

At the Corne11 Workshop very rough cost estimates were made for the total complex. The infrastucture including buildings, power, injector, experimental facilities, magnet factory, etc was about .5 billion dollars. Tunnel costs ranged anywhere from 200 dollars per foot for a three foot diameter cut and fill system, to 400 dollars per foot for a 7 foot diameter cut and fill, to 700 dollars per foot for an 8 foot diameter bored tunnel. The numbers used in figure 4 take about the average of the above. The accelerator components and magnets make up the rest of the costs presented. As can be seen in 


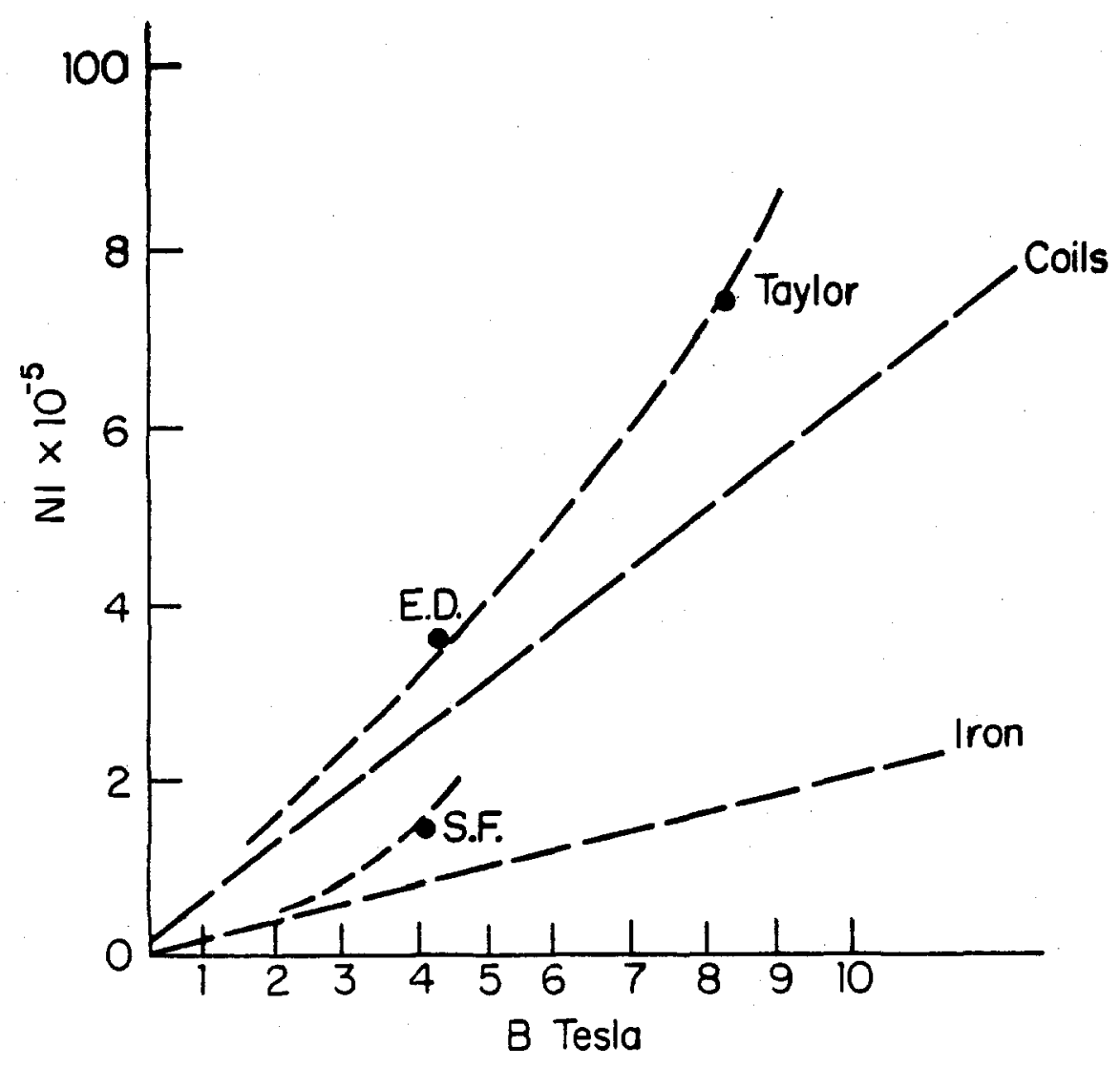

Fig. 2. Ampere turns versus magnetic field for various design magnets. The line marked "Iron" is for an iron-dominated field with infinite permeability. The real superferric magnets (S.F.) lie above the line because of finite permeability and saturation.

The line marked "Coils" is for a single coll magnet design with no iron. The real magnets (E.D. = Energy Doubler, Taylor $=$ LBL magnet design, both with 2-in. bore) lie above the line because the cross section of the coils must be shaped (cosine) to give good field over an extended region, also the coils have finite size because of limited current density. 


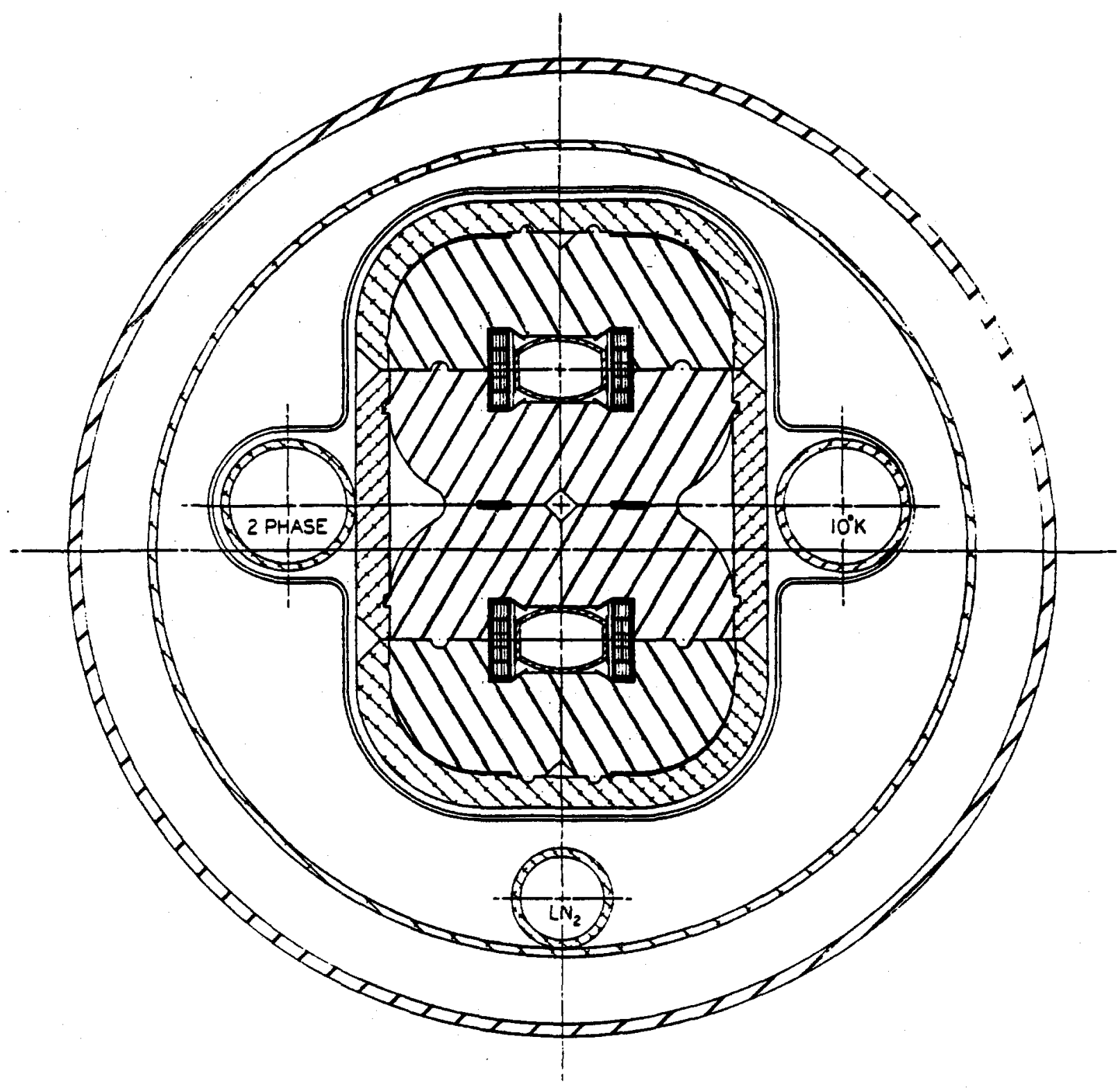

Fig. 3. A 3-Tesla magnet design. The bore tube, conductor, and casing around steel laminations are aluminum. Each coll package is 1.25 high by 0.375 inches wide. 
Figure 4 all the different designs add up to about the same total. As each design is studied in more detail, significant differences will develop.

5. Conclusion

The important conclusion is that the U.S. is ready to proceed with design and construction of a $20 \mathrm{TeV}$ on $20 \mathrm{TeV}$ proton-proton collider. It appears that the U.S. government is willing to support such a project. Hopefully such a facility can be in operation by 1992 . 


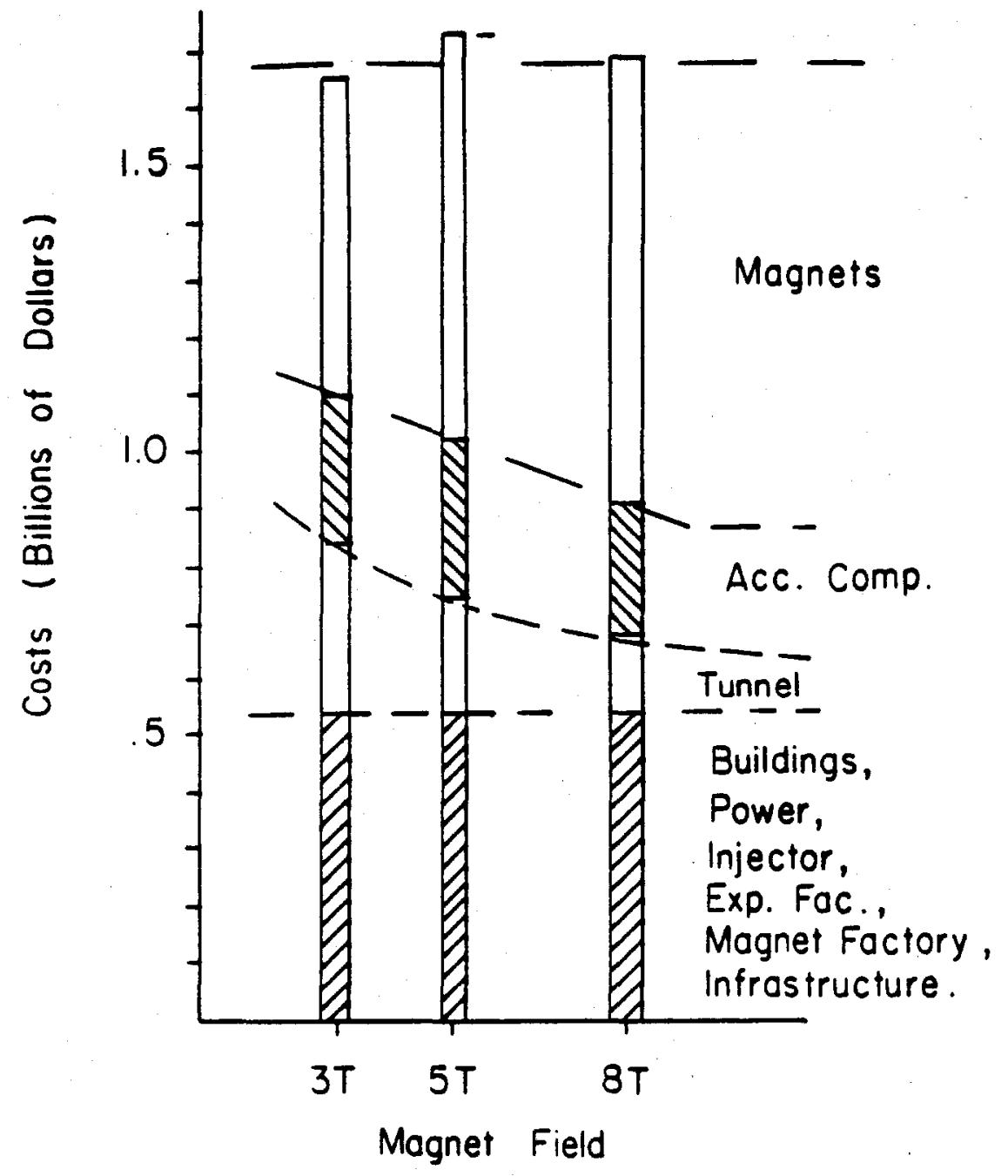

Fig. 4. Total accelerator facility costs versus magnet field used. The data is taken from the Cornell Workshop. 